www.jmscr.igmpublication.org

Index Copernicus Value: 79.54

ISSN (e)-2347-176x ISSN (p) 2455-0450

crossrefDOI: https://dx.doi.org/10.18535/jmscr/v7i3.66

\title{
Outcome of a Rare Case of Early Stage Lung Cancer in a Tertiary Care Center
}

\author{
Authors \\ Dr Joydeep Singh Vasant ${ }^{1}$, Dr Ashok Kumar Chauhan ${ }^{2}$, Dr Paramjit Kaur ${ }^{3}$ \\ Dr Jyoti Pannu ${ }^{4}$, Dr Roshani Vyas ${ }^{5}$ \\ $1,4,53{ }^{\text {rd }}$ year PG student, ${ }^{2}$ Senior Professor, ${ }^{3}$ Professor \\ Department of Radiotherapy, PGIMS, Rohtak, India
}

\section{Introduction}

As per GLOBOCAN 2018, lung cancer is the most common cancer in the world at $11.6 \%$ and has the highest mortality. In India it is the fourth most common cancer comprising of $5.9 \%$ of all the new cases and is responsible for $9.3 \%$ of all cancer related mortality in both sexes. ${ }^{1}$ As in developing countries most of the patients present in locally advanced stages. The overall 5-year survival rate of lung cancer is dismal with approximately 15 per cent in developed countries and 5 per cent in developing countries. ${ }^{2}$ In the department of Radiotherapy PGIMS, Rohtak carcinoma lung constituted $8.1 \%$ of all the cancer patients registered of which less than $1 \%$ are early stage. ${ }^{3}$ Surgery is the standard mode of treatment of patients with stage I and II tumors and for selective patients with stage III tumors. But only $20 \%$ of all the patients presenting with lung cancer are suitable for surgery. ${ }^{4}$ Conventional fractionated radiotherapy is recommended, with reported 5-year local control and overall survival rates ranging from $30 \%$ to $50 \%$ and $10 \%$ to $30 \%$ respectively in stage I/II Non-Small cell lung carcinoma. 5

\section{Case Presentation}

A 70 year old man with a history of smoking bidi and hookah since 40 years presented to the Department of Radiotherapy with the chief complaint of productive cough. The patient had undergone left upper lobectomy 1 month before presenting to us. The stage of the patient was $\mathrm{T}_{2 \mathrm{~b}} \mathrm{~N}_{0} \mathrm{M}_{0}$, Stage IIA, squamous cell carcinoma. In view of compromised margins as per the postoperative histopathology report the patient was panned for Radiotherapy. Keeping in view the general condition and age of the patient, the patient was given Radiotherapy 42 Gy in 21 fractions over 4.1 weeks, by conventional simulation on cobalt 60 . The treatment was tolerated well \& the patient was put on monthly follow up. Two post Radiotherapy CECTs were done at 3 and 6 months respectively and both of which revealed no residual or recurrent disease. The patient is still on follow up with no chief complaint of any respiratory distress. The overall survival of the patient is 15 months.

\section{Discussion}

As already described lung cancer is the most common cause of cancer related mortality all over 
the world. In developing countries like India only $20 \%$ patients present in early stage disease. But only $20 \%$ of the early stage patients are operable. The outcome of surgery even in advanced stage operable lung cancer patients has acceptable postoperative mortality rates. ${ }^{6}$ Surgically resected stage I NSCLC has only a 70\% 5-year survival and a $55-75 \%$ recurrence rate re, $^{7,9,10}$. Five-year survival after surgical resection decreases to 40$50 \%$ for stage II disease ${ }^{11}$. The large database informing the most recent international lung cancer staging system demonstrated 5-year survival for stages IA, IB, IIA and IIB of $73 \%$, $58 \%, 46 \%$ and $36 \%$ respectively $^{7}$. Unfortunately, lung cancer is detected in an advanced stage in approximately $70 \%$ of patients, making it one of the leading causes of death in America, with only a $16 \%$ overall 5 -year survival ${ }^{12}$.In early stage operable lung cancer, lobectomy is considered a superior approach when compared to sub-lobar resection ${ }^{13}$. Post operative Radiotherapy in positive margins is associated with superior results in terms of survival. ${ }^{14}$

\section{Conclusion}

We are hereby reporting a rare case of early stage squamous cell carcinoma lung in a tertiary care centre which has most of its patients from rural areas who mostly present in locally advanced stages which is due to lack of awareness, and asymptomatic early stages of the disease. The patient reported post-operatively, and due to positive margins the patient was given Radiotherapy, the dose of which was decided keeping view the patients age. CECT revealed no residual/ recurrent disease and there was no treatment related toxicity observed.

\section{References}

1. Ferlay J, Soeriomataram I, Ervik M, Dikshit R, Eser S, Mathers C, et al. GLOBOCAN 2018 v1.0, Cancer Incidence and Mortality Worldwide: IARC Cancer Base No. 11. Lyon, France International Agency for Research on Cancer; 2018.
2. Parkin DM, Bray F. Ferlay J, Pisani P. Global cancer statistics, 2002. CA Cncer J Clin. 2005;55:74-108

3. Pt. B. D. Sharma PGIMS, Rohtak (India). Data for the year 2017. Retrieved in January 2018 from Radiotherapy OPD record section.

4. Pearson FG. Current status of surgical resection for lung cancer. Chest 1997;106:337.

5. Singh N, Aggarwal AN, Gupta D, Behera D, Jindal SK. Unchanging clinicepidemiological profile of lung cancer in North India over three decades. Cancer Epidemiol. 2009;10:1033-4

6. Yamanashi K, Okumura N, Takahashi A, Nakashima T, Matsuoka T. Surgical andsurvival outcomes of lung cancer patients with intratumoral lung abscesses. JCardiothorac Surg. 2017 May 26;12(1):44.

7. Mountain CF. Revisions in the International System for Staging Lung Cancer. Chest. 1997;111(6):1710-1717

8. Pairolero PC, Williams DE, Bergstralh EJ, et al. Postsurgical stage I bronchogenic carcinoma: morbid implications of recurrent disease. Ann Thorac Surg. 1984;38(4):331-338.

9. Feld R, Rubinstein LV, Weisenberger TH. Sites of recurrence in resected stage I nonsmall-cell lung cancer: a guide for future studies. J ClinOncol. 1984;2(12):13521358.

10. Goldstraw P, Crowley J, Chansky K, et al. The IASLC Lung Cancer Staging Project: proposals for the revision of the TNM stage groupings in the forthcoming (seventh) edition of the TNM Classification of malignant tumours. J ThoracOncol. 2007;2(8):706-714.

11. Scott WJ, Howington J, Feigenberg S, et al. Treatment of non-small cell lung cancer stage I and stage II: ACCP evidence-based 
clinical practice guidelines (2nd edition) Chest. 2007;132(3 Suppl):234S-242S.

12. Jemal A, Siegel R, Xu J, et al. Cancer statistics, 2010. CA Cancer J Clin. 2010;60(5):277-300.

13. Ginsberg RJ, Rubinstein LV. Randomized trial of lobectomy versus limited resection for T1 N0 non-small cell lung cancer. Lung Cancer Study Group. Ann Thorac Surg. 1995;60(3):615-622. discussion 622-3.

14. Wang HH, Deng L, Wen QL, et al. Early postoperative radiotherapy is associated with improved outcomesover late postoperative radiotherapy in the management of completely resected(R0) Stage IIIA-N2 non-small cell lung cancer. Oncotarget. 2017 May23;8(38):6299863013. 